\title{
Tracking the air exhaled by an opera singer
}

\author{
Philippe Bourrianne $\odot,{ }^{1}$ Paul R. Kaneelil $\odot,{ }^{1}$ Manouk Abkarian, ${ }^{2}$ and Howard A. Stone ${ }^{1}{ }^{1}$ \\ ${ }^{1}$ Department of Mechanical and Aerospace Engineering, Princeton University, \\ Princeton, New Jersey 08544, USA \\ ${ }^{2}$ Centre de Biologie Structurale, CNRS UMR 5048, INSERM UMR 1054, \\ University of Montpellier, 34090 Montpellier, France
}

(Received 6 August 2021; published 15 November 2021)

\begin{abstract}
This paper is associated with a video winner of a 2020 American Physical Society's Division of Fluid Dynamics (DFD) Milton van Dyke Award for work presented at the DFD Gallery of Fluid Motion. The original video is available online at the Gallery of Fluid Motion, https://doi.org/10.1103/APS.DFD.2020.GFM.V0067.
\end{abstract}

DOI: 10.1103/PhysRevFluids.6.110503

Opera singers are known for their ability to control their respiration and exhalations during a musical performance. However, air flows exhaled by singers were questioned during the COVID-19 pandemic as clusters of infections were identified within choirs due to the release of pathogenic droplets during rehearsals [1]. Indeed, singing leads to an increased number of aerosol droplets released by a person [2]. The expiratory air flows from a singer are of interest as there is a possibility of contaminated droplets to be transported by the exhaled air [3].

We observed the air exhaled by a mezzosoprano singer during her performance of an Armenian lullaby "Oror." We use a high-speed infrared camera (FLIR X6900SC) operating in the midwave range of the infrared spectrum $(1.5-5 \mu \mathrm{m})$. The use of a filter in the absorption range of $\mathrm{CO}_{2}$ $(4.2 \mu \mathrm{m})$ enables tracking the warm exhaled $\mathrm{CO}_{2}$. The opera singer sat beside a dark nonreflective curtain that provided a uniform background at the ambient temperature. As seen in the image sequence of Fig. 1, the infrared imaging captures the warm face of the singer and the warm exhaled $\mathrm{CO}_{2}$. The spatial extent of the exhaled $\mathrm{CO}_{2}$ can, thus, be estimated. In Fig. 1, the exhaled air is detected at around $1 \mathrm{~m}$ from the singer within a few seconds after the beginning of the song $(t=0 \mathrm{~s})$.

During the performance, three distinct air flows can be identified as reported in the closeup views in Fig. 2. First, breathing generates rapid air jets emanating from the nose as seen in the sequence of images in Fig. 2(a). The initial velocity of the breathing jet is about $1 \mathrm{~m} / \mathrm{s}$ and leads to a straight downward trajectory driven by the inertia of the air flows. Then, the singer performs most of the song with an open mouth, singing vowel-based sounds of frequent occurrence in the opera. As she maintains tonalities during 10-20 s without any inhalation, her performance requires a low value of expiratory flow-rate $(Q \approx 10 \mathrm{l} / \mathrm{min})$ due to the intrinsic limit of her lung capacity. The remarkable control of the expiratory flow by the opera singer during her performance and her wide-open mouth lead to air flows slower than breathing with initial velocity around $0.3 \mathrm{~m} / \mathrm{s}$. The warm $\mathrm{CO}_{2}$ cloud exhaled during the performance rises as shown by the curved trajectory (white arrow) in Fig. 2(b) as buoyancy dominates the reduced inertia of the exhaled air jet. However, a third kind of air flow

Published by the American Physical Society under the terms of the Creative Commons Attribution 4.0 International license. Further distribution of this work must maintain attribution to the author(s) and the published article's title, journal citation, and DOI. 

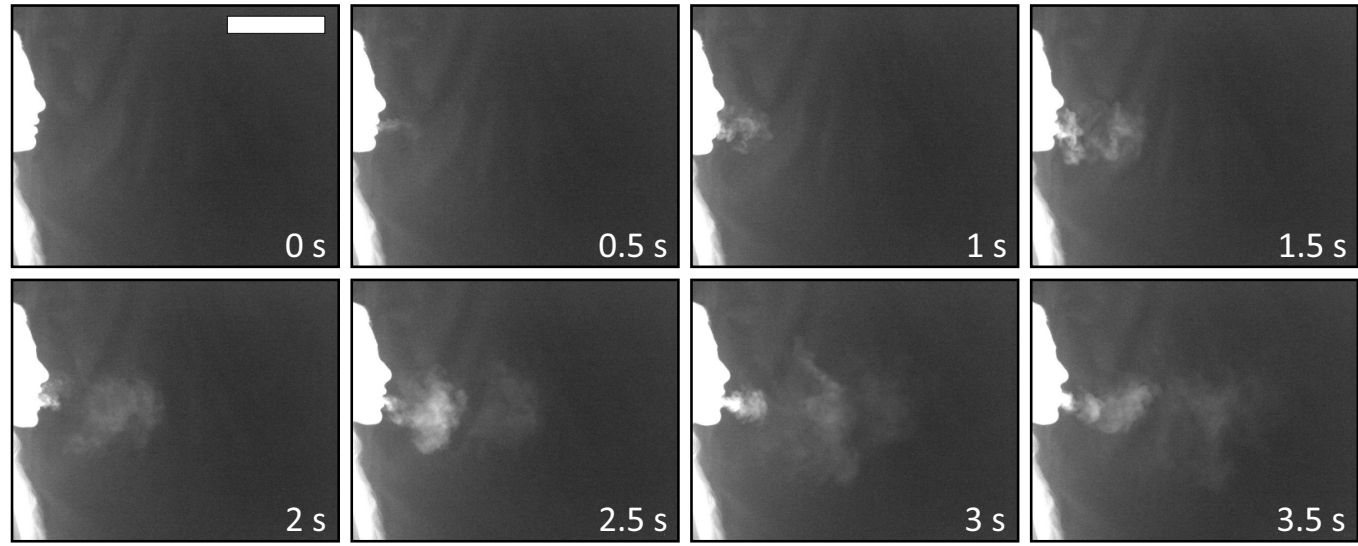

FIG. 1. Tracking the exhaled $\mathrm{CO}_{2}$ from an opera singer. Sequence of infrared images (time step of $500 \mathrm{~ms}$ ) of a mezzosoprano singing the Armenian lullaby Oror. The warm exhaled $\mathrm{CO}_{2}$ emanating from the singer traveled distances close to $1 \mathrm{~m}$ within a few seconds. The scale bar represents $30 \mathrm{~cm}$.

can be identified when the singer closes her mouth during the performance. The pronunciation of consonant sounds, such as plosives, requires closing the lips, which leads to a significant reduction of the mouth opening and, thus, to the generation of a rapid air jet with velocities around $10 \mathrm{~m} / \mathrm{s}$ as seen in Fig. 2(c) where the air jet reaches distances of $10 \mathrm{~cm}$ within $10 \mathrm{~ms}$. When singing consonant
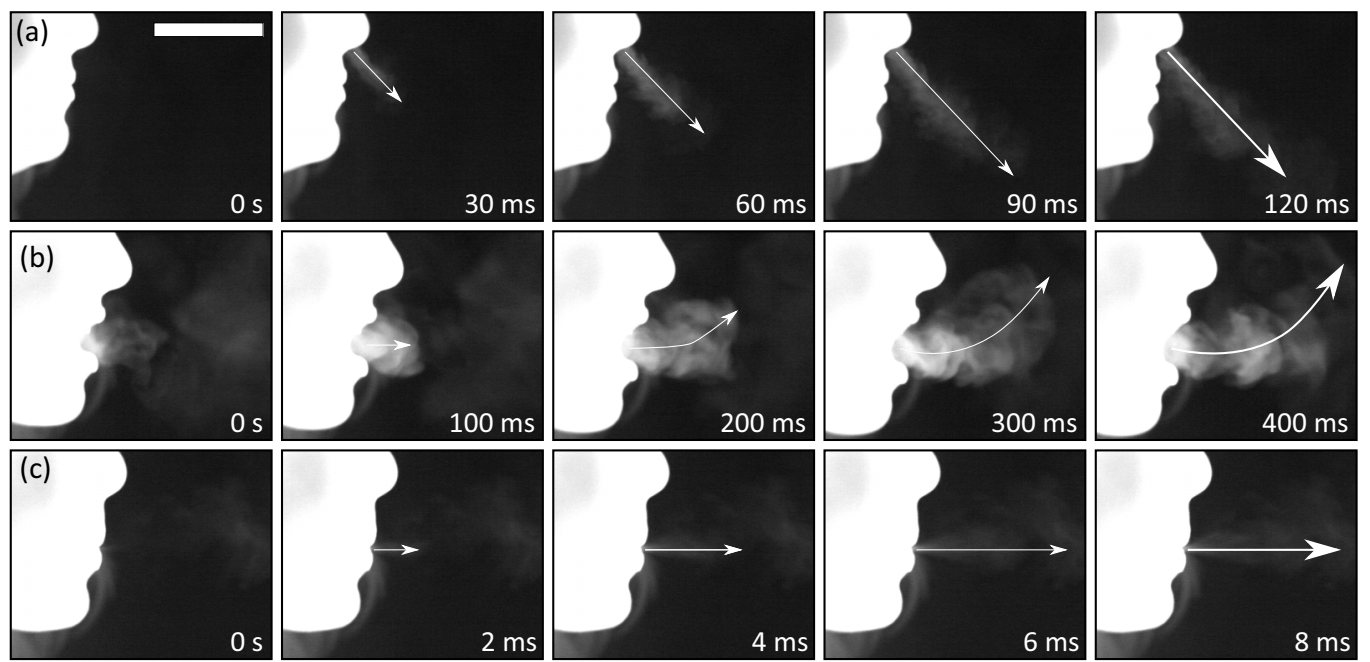

FIG. 2. Different air flows during the performance. (a) Sequence of infrared images (time step of $100 \mathrm{~ms}$ ) tracking the exhaled $\mathrm{CO}_{2}$ as the singer breathes from the nose prior to the performance. The warm air is exhaled at an initial velocity around $1 \mathrm{~m} / \mathrm{s}$. The front of the exhaled air has a straight downward trajectory as shown by the white arrow depicting the trajectory of the front of the exhaled air jet. The scale bar represents $10 \mathrm{~cm}$. (b) Sequence of infrared images (time step of $100 \mathrm{~ms}$ ) tracking the exhaled $\mathrm{CO}_{2}$ as the singer sings with a wide-open mouth. The warm air is exhaled at an initial velocity around $0.3 \mathrm{~m} / \mathrm{s}$. The curved trajectory of the air front (white arrow) demonstrates the redirection of the warm exhaled air due to the buoyancy. (c) Sequence of infrared images (time step of $100 \mathrm{~ms}$ ) tracking the exhaled $\mathrm{CO}_{2}$ as the singer starts singing with a closed mouth. The warm air is exhaled at an initial velocity above $10 \mathrm{~m} / \mathrm{s}$. The front of the air jet has a horizontal straight trajectory (white arrow). 
sounds, the opera singer generates rapid air jets reaching velocities similar to the ones observed during the pronunciation of spoken plosives [4]. This observation suggests that singing consonant sounds and plosives might enhance the transport of possible pathogenic droplets emanating from a singer.

We thank E. Bowman and the MET Orchestra Musicians in New York City for their active support and extraordinary interest. In particular, we thank I. Leonard for her interest and her performance. Many thanks to musicians from the MET Orchestra including S. Mortimore, D. LeBlanc, B. Currie, P. Díaz, D. Austin, and R. Riccomini and to opera singers A. Blue, I. Leonard, and C. Goerke. We thank FLIR, M. Roselli, and T. McDowd for the gracious loan of the infrared camera. Finally, we thank S. Levin, A. Moravcsik, and V. Poor from Princeton University for their advice and support. We thank the NSF for support via Grants No. CBET 2029370 and No. CBET 2116184.

[1] S. L. Miller, W. W. Nazaroff, J. L. Jimenez, A. Boerstra, G. Buonanno, S. J. Dancer, J. Kurnitski, L. C. Marr, L. Morawska, and C. Noakes, Transmission of SARS-CoV-2 by inhalation of respiratory aerosol in the Skagit Valley Chorale superspreading event, Indoor Air 31, 314 (2021).

[2] M. Alsved, A. Matamis, R. Bohlin, M. Richter, P.-E. Bengtsson, C.-J. Fraenkel, P. Medstrand, and J. Löndahl, Exhaled respiratory particles during singing and talking, Aerosol Sci. Technol. 54, 1245 (2020).

[3] W. F. Wells, On air-borne infection. Study II. Droplets and droplet nuclei, Am. J. Epidemiol. 20, 611 (1934).

[4] M. Abkarian, S. Mendez, N. Xue, F. Yang, and H. A. Stone, Speech can produce jet-like transport relevant to asymptomatic spreading of virus, Proc. Natl. Acad. Sci. USA 117, 25237 (2020). 